\title{
Nestin-positive microvessel density is an independent prognostic factor in breast cancer
}

\author{
ALEKSANDRA NOWAK $^{1}$, JEDRZEJ GRZEGRZOLKA $^{1}$, MARIA PAPROCKA $^{2}$, ALEKSANDRA PIOTROWSKA $^{1}$, \\ JANUSZ RYS $^{3}$, RAFAL MATKOWSKI ${ }^{4,6}$ and PIOTR DZIEGIEL ${ }^{1,5}$ \\ ${ }^{1}$ Department of Histology and Embryology, Wroclaw Medical University; ${ }^{2}$ Laboratory of Cellular Interactions, \\ Ludwik Hirszfeld Institute of Immunology and Experimental Therapy, Polish Academy of Sciences, Wroclaw; \\ ${ }^{3}$ Department of Tumour Pathology, Centre of Oncology, Maria Sklodowska-Curie Memorial Institute, \\ Cracow Branch; ${ }^{4}$ Breast Unit, Department of Surgical Oncology, Lower Silesian Oncology Centre; \\ ${ }^{5}$ Department of Physiotherapy, University School of Physical Education; ${ }^{6}$ Department of Oncology \\ and Surgical Oncology, Wroclaw Medical University, Wroclaw, Poland
}

Received March 16, 2017; Accepted May 24, 2017

DOI: $10.3892 /$ ijo.2017.4057

\begin{abstract}
The process of angiogenesis based on new vessel formation within the tumour area plays a significant role in the progression of breast cancer. Nestin is an intermediate filament protein and participates in the cytoskeleton organization. Nestin expression in the endothelium of blood vessels is mainly limited to newly forming vessels, thus being a more specific marker of angiogenesis than the commonly used vascular antigens. The aim of this study was to determine the prognostic value of nestin-positive microvessel density (Nes ${ }^{+} \mathrm{MVD}$ ) in breast cancer patients and to confirm that nestin expression is related to newly forming tumour vessels. In this study, 137 cases of ductal breast carcinoma and 19 cases of non-malignant breast tissue lesions (NBTLs) were examined. Immunohistochemical reactions were performed on paraffin sections using antibodies against nestin, CD34 and CD31 antigens. For each marker, the microvessel density (MVD) was determined. Nestin expression was also examined in human endothelial cell lines (HUVEC-SVT, HMEC-1 and HEPC-CB.1) representing a different level of endothelial cell maturity. HUVEC-SVT and HMEC-1 cells represent the endothelium of mature vessels, whereas HEPC-CB.1 cells represent the early endothelial progenitor cells (EPCs). We have demonstrated that high $\mathrm{Nes}^{+} \mathrm{MVD}$ may be associated with a more aggressive course of the disease and a poorer prognosis. We have also found a higher Nes ${ }^{+} \mathrm{MVD}$ in the cases with lymph node metastases, with higher histological grade, with advancedstage disease and with the triple-negative (TN) breast cancer. In addition, nestin expression in vessels was associated with a shorter overall survival (OS) and earlier relapse, and in the case of OS nestin was an independent prognostic factor. Finally, we
\end{abstract}

Correspondence to: Ms. Aleksandra Nowak, Department of Histology and Embryology, Wroclaw Medical University, Chalubinskiego 6a, 50-368 Wroclaw, Poland

E-mail: alexandra.m.nowak@gmail.com

Key words: nestin, angiogenesis, breast cancer further confirmed that nestin expression in endothelial cells reflects a progenitor nature of newly forming vessels.

\section{Introduction}

Breast cancer is the most commonly diagnosed malignant cancer in women and the leading cause of death among women with cancers. The formation of a new vascular network known as tumour angiogenesis plays a key role in the progression of this tumour. The process was first described in 1971 by Folkman, who postulated that the tumour growth and metastasis depends on the number of newly formed blood vessels (1). This hypothesis became the basis for further research demonstrating that the 'angiogenic switch' is an integral part of most cancer progression (2). The administration of adjuvant anti-angiogenic therapy had positive results in the case of colorectal, breast, kidney and pancreatic cancers, and non-small cell lung carcinoma $(3,4)$.

The most commonly used method to quantify intratumoural angiogenesis in histological specimens is the assessment of MVD. The MVD can be assessed by counting immunolabelled vessels stained with antibodies against endothelial cell antigens, e.g., CD31 and CD34 (5). This method was developed by Weidner et al who also confirmed that in the case of invasive ductal carcinoma (IDC) high MVD is associated with the incidence of regional lymph node and distant metastases (6). The results of the meta-analysis confirmed the prognostic value of MVD assessment in breast cancer (5). However, the evaluation of tumour angiogenesis with MVD has some limitations. One of them is the fact that commonly used markers are expressed not only in newly forming vessels but also in mature vessels present in body tissues and organs (7).

Nestin is a type VI intermediate filament (IF) protein and participates in the cytoskeleton organization (8). Its expression is typical of neuroepithelial stem cells (8), but it is also present in progenitor (9-11) muscle $(9)$, endothelial $(12,13)$ and cancer cells $(14,15)$. In the cell, nestin expression is transient and following cell differentiation it is downregulated and replaced by tissue-specific IFs (16). It is suggested that nestin 
expression in blood vessels is mainly limited to the proliferating and newly forming vessels, which makes nestin a more specific marker of angiogenesis than commonly used CD34 and CD31 (17-20).

Due to nestin progenitor features and proven expression in blood vessels we suspected that it may be a reliable marker for angiogenesis evaluation in IDC patients. Hence, the aim of the present study was to assess nestin-positive microvessel density (Nes ${ }^{+} \mathrm{MVD}$ ) and to determine its prognostic value in patients with IDC. We also aimed at determining whether nestin is a marker of newly forming and poorly differentiated blood vessels. Accordingly, we compared Nes ${ }^{+} \mathrm{MVD}$ with the density of newly forming CD $34^{+}$vessels (CD34 $\left.{ }^{+} \mathrm{MVD}\right)$ and mature $\mathrm{CD} 31^{+}$vessels $\left(\mathrm{CD} 31^{+} \mathrm{MVD}\right)$. To confirm whether the expression of nestin is increased in endothelial progenitor cells (EPCs) we developed an in vitro model consisting of human endothelial cell lines representing a different level of maturity. HUVEC-SVT and HMEC-1 cells represent the endothelial cells (EC) of mature venous vessels and capillaries, whereas HEPC-CB.1 cells are the early EPCs.

\section{Materials and methods}

Tissue samples. The study was conducted on archival paraffin-embedded ductal breast carcinoma samples $(n=137)$ and NBTLs $(n=19)$ collected during resection procedures at The Maria Sklodowska Curie Memorial Cancer Centre and Institute of Oncology in Cracow and at The Lower Silesian Oncology Centre in Wroclaw from 1999 to 2013. From 137 investigated cancer patients, 26 developed pre-invasive in situ carcinoma (DCIS), whereas 111 developed invasive cancer (IDC). The investigated cases were categorized into 4 groups according to their invasiveness (Table I): NBTLs, ductal carcinoma in situ (DCIS), lymph node-negative invasive ductal carcinoma (IDC $\mathrm{N}^{-}$) and lymph node-positive invasive ductal carcinoma (IDC $\mathrm{N}^{+}$). The clinical, pathological and survival data were obtained only for IDC patients $(n=111)$ from the archives of the hospital and are listed in Table II. From these 111 invasive cases, 23 patients died from the disease and 25 patients had recurrence (Table II). The study was approved by the Commission of Bioethics of the Wroclaw Medical University, Poland.

Human endothelial cell lines. To determine the expression level of nestin human immortalized ECs (HUVEC-SVT, HMEC-1) and EPCs (HEPC-CB.1) were selected. The HMEC-1 cells (ATCC, Washington, CO, USA) were cultured in MCDB 131 (Invitrogen, Carlsbad, CA, USA) supplemented with $10 \%$ fetal bovine serum (FBS, Sigma, St. Louis, MO, USA), $10 \mathrm{ng} / \mathrm{ml}$ epidermal growth factor (EGF, Invitrogen), $1 \mu \mathrm{g} / \mathrm{ml}$ hydrocortisone (Sigma) and $10 \mathrm{mM}$ L-glutamine (Invitrogen). HUVEC-SVT and HEPC-CB.1 cells (both courtesy of Dr M. Paprocka, Ludwik Hirszfeld Institute of Immunology and Experimental Therapy of the Polish Academy of Sciences, Wroclaw, Poland) were grown in Dulbecco's modified Eagle's medium (DMEM, Lonza, Basel, Switzerland) with $4.5 \mathrm{~g} / 1$ glucose, $25 \mathrm{mM}$ HEPES sodium pyruvate without L-glutamine supplemented with $10 \%$ fetal bovine serum (Merck, Millerica, MA, USA), 2 mM L-glutamine and antibiotics (Sigma). All of the studies utilized cell passages 18-26. The investigated cell lines exhibit different phenotypes of endothelial cells. Human umbilical vein endothelial cells (HUVEC-SVT) are immortalised cells isolated from the large vessel representing macrovascular phenotype (21). Immortalised human microvascular endothelial cells (HMEC-1) originate in dermal microvasculature and show the characteristics similar to ECs present in tumour environment (21). HEPC-CB.1 cells are immortalized early human EPCs isolated from the cord blood (22).

Immunohistochemistry (IHC). Immunohistochemical reactions were performed on $4-\mu \mathrm{m}$ thick paraffin sections using Autostainer Link48 (Dako, Glostrup, Denmark) with a panel of mouse-anti human monoclonal antibodies against: nestin (dilution 1:100, OBT1610, Bio-Rad, Hercules, CA, ISA), CD31 (ready-to-use, IR610, Dako), CD34 (ready-to-use, IR632, Dako) estrogen receptor (ER), clone 1D5 (ready-to-use, IR654; Dako) and progesterone receptor (PR) clone 636 (readyto-use, IR068; Dako). The sections were boiled in EnVision FLEX Target Retrieval Solution ( $\mathrm{pH} 9.0,97^{\circ} \mathrm{C}, 20 \mathrm{~min}$ ) using Pre-Treatment Link Platform (both from Dako). Activity of endogenous peroxidase was blocked by $5 \mathrm{~min}$ incubation with EnVision FLEX Peroxidase-Blocking Reagent (Dako). The samples were incubated with primary antibodies for $20 \mathrm{~min}$ at room temperature (RT) and then incubated with EnVision FLEX/HRP for 20 min (Dako). 3,3'-diaminobenzidine (DAB, Dako) was utilized as the peroxidase substrate and the sections were incubated for $10 \mathrm{~min}$. Finally, all slides were counterstained with EnVision FLEX Hematoxylin (Dako) for $5 \mathrm{~min}$. After dehydration in graded ethanol concentrations (70, 96 and $99.8 \%$ ) and in xylene, slides were closed with coverslips in Dako mounting medium (Dako). Human epidermal growth factor receptor 2 (HER2) expression status was determined using HercepTest and HER2 FISH pharmDx kit (both from Dako), according to the manufacturer's instructions.

Examination of IHC reactions. The IHC reactions were evaluated with a BX-41 light microscope (Olympus, Tokyo, Japan). The MVD was assessed for each investigated antigen i.e., nestin, CD31 and CD34 according to the Weidner method (6). Firstly, the slides were examined under low magnification (x100) to identify three areas with the highest vascular density (hot-spots). Then, under magnification $\mathrm{x} 400$ stained vessels were counted. The final score for each slide was presented as a mean number of vessels per $\mathrm{mm}^{2}$. Any stained EC or ECs clusters were counted as a single microvessel, even in the absence of vessel lumen (6). The status of ER and PR was scored 0-3 points, depending on the percentage of positive cells ( 0 points, no reactions; 1 point, $1-10 \%$; 2 points, $11-50 \%$; 3 points, 51-100\% stained cells) (23). The expression of HER2 was evaluated using a scale that considers both the intensity of the membrane reaction and the percentage of positive tumour cells (24).

Immunocytochemistry (ICC) and immunofluorescence (IF). Investigated endothelial cell lines were grown on glass coverslips for $24 \mathrm{~h}$ at $37^{\circ} \mathrm{C}$. After $24 \mathrm{~h}$, cells were washed with phosphate-buffered saline, fixed in $4 \%$ paraformaldehyde and permabilised with $0.2 \%$ Triton X. The IHC of fixed cells was performed with anti-nestin antibody in Dako Autostainer 
Table I. Groups of patients according to tumour invasiveness.

\begin{tabular}{ll}
\hline Histological type & $\mathrm{n}$ \\
\hline Non malignant breast tissue lesions & 19 \\
Ductal carcinoma in situ & 26 \\
Invasive ductal carcinoma - lymph node negative & 62 \\
Invasive ductal carcinoma - lymph node positive & 49 \\
\hline
\end{tabular}

Link48 (Dako) according to the procedure described above. The slides were incubated with primary antibodies for $20 \mathrm{~min}$ at RT, and then incubated with EnVision FLEX (Dako) to visualize the antigens. For IF the cell lines were cultured and fixed as stated above. All slides were incubated at $4^{\circ} \mathrm{C}$ overnight with monoclonal antibody against nestin (Bio-Rad) and resolved in antibody diluent (Dako) in the concentration of 1:100. As a secondary antibody donkey anti-mouse antibody conjugated with rhodamine (1:2,000, polyclonal; 715-025-151 Jackson ImmunoResearch Laboratories, Inc., West Grove, PA, USA) was applied. The slides were covered with ProLong ${ }^{\circledR}$ Gold Antifade Mountant mounting medium (Molecular Probes, Eugene, OR, USA) with 4',6-diamidino-2-phenylindole (DAPI) and viewed and imaged with a BX51 fluorescence microscope (Olympus).

$R N A$ isolation and real-time PCR reactions. Total RNA from HUVEC-SVT, HMEC-1 and HEPC-CB.1 cell lines was isolated using the RNeasy Mini kit (Qiagen, Hilden, Germany) according to the manufacturer's instructions. To eliminate the genomic DNA, the protocol included on-column DNase digestion. RNA concentration and purity were measured using the NanoDrop1000 spectrophotometer (NanoDrop Technologies, Wilmington, DE, USA). The absorbance was measured at 260-280 nm. The first-strand cDNA was synthesized using the High-Capacity cDNA Reverse Transcription kits (Applied Biosystems, Foster City, CA, USA). The relative nestin gene (NES) mRNA expression level was determined by quantitative real-time PCR using the 7500 Real-Time PCR system and the iTaq Universal Probes Supermix (Bio-Rad), according to the manufacturer's protocol. We applied the following human Taqman Gene Expression Assays: NES Hs04187831_g1 for nestin and ACTB Hs99999903_ml for $\beta$-actin (Applied Biosystems). Since $\beta$-actin is a housekeeping gene, it was used as a reference for determining NES expression in the analyzed human endothelial cell lines. The reactions were carried out in triplicate in the following conditions: initial denaturation at $95^{\circ} \mathrm{C}$ for $10 \mathrm{~min}$, followed by 45 cycles of denaturation at $95^{\circ} \mathrm{C}$ for $15 \mathrm{sec}$, and annealing and elongation at $60^{\circ} \mathrm{C}$ for $60 \mathrm{sec}$. The relative mRNA expression level of the NES gene was calculated with the $\Delta \Delta \mathrm{Ct}$ method (25).

Flow cytometry $(F C)$. For flow cytometric immunophenotyping of intercellular nestin, cells were fixed and permeabilized with BD Cytofix/Cytoperm ${ }^{\mathrm{TM}}$ (Becton-Dickinson, CA, USA) according to the manufacturer's instructions. Subsequently, the cells were stained with monoclonal antibody against human nestin (1:100; OBT1610) for $20 \mathrm{~min} / \mathrm{RT}$ and immunolabelled with sheep anti-mouse secondary antibody conjugated with
Table II. Clinicopathological characteristics of IDC patients.

\begin{tabular}{lcr}
\hline Parameters & $\mathrm{n}$ & $\%$ \\
\hline Age & & \\
$\leq 50$ & 34 & 30.6 \\
$>50$ & 77 & 69.4 \\
Menopausal status & & \\
Pre- & 36 & 32.4 \\
Post- & 73 & 65.8 \\
No data & 2 & 1.8
\end{tabular}

Tumour size

T1 61

$\mathrm{T} 2$

T3

T4

No data

Lymph nodes

Negative 62

55.9

Positive

Grade

1

2

54.1

3

36.0

pTNM

I + II

III + IV

15.3

No data

ER

Negative 28

25.2

Positive

74.8

PR

Negative $\quad 38$

34.2

Positive 73

65.8

HER2

Negative

60.4

Positive

39.6

Triple-negative

Yes

15.3

No

84.7

Overall survival

Deaths 23

Alive

77.5

No data

Event-free survival

Recurrence

No recurrence

74.8

No data

2.7

ER, estrogen receptor; PR, progesterone receptor; HER2, human epidermal growth factor receptor. 

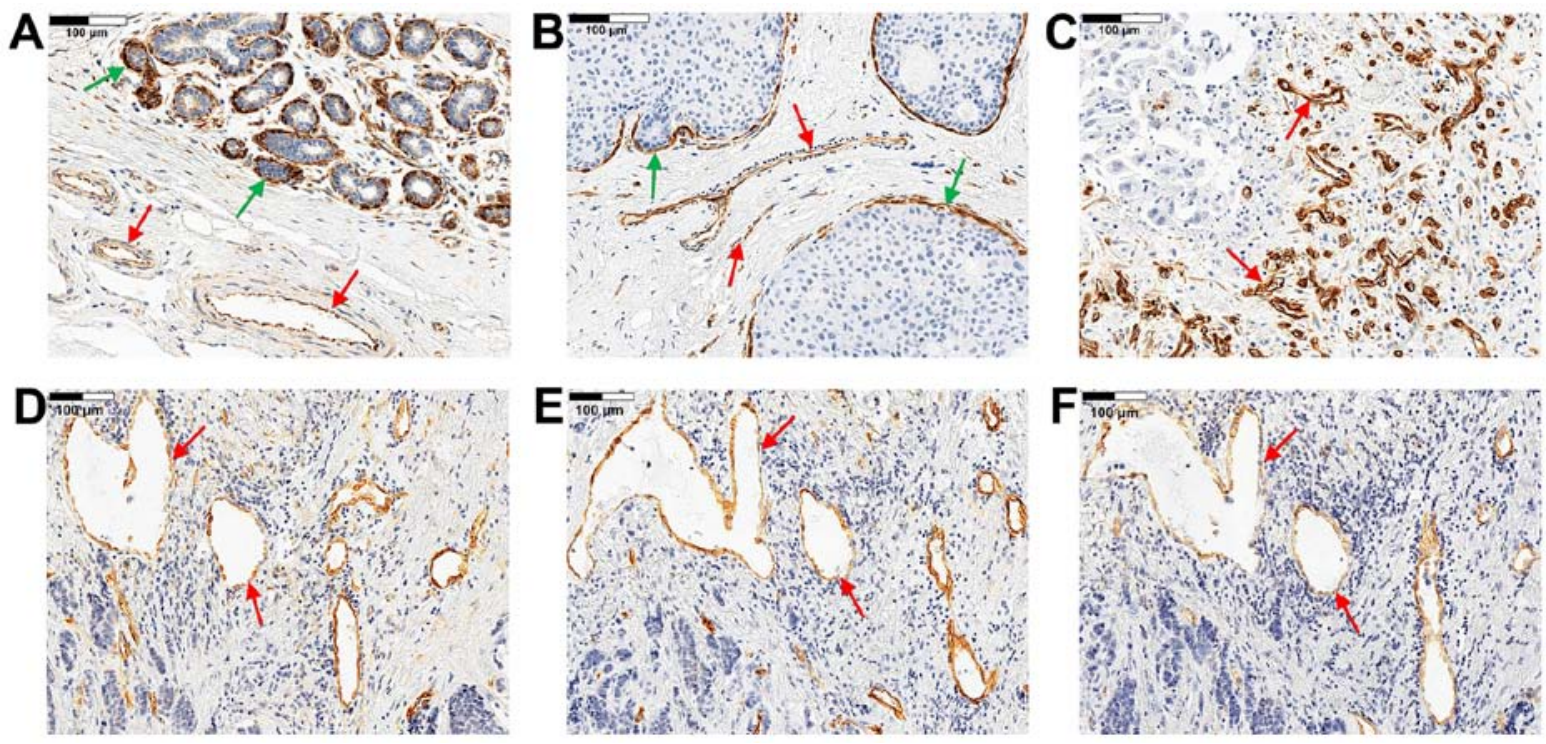

Figure 1. Nestin expression (red arrows) in blood vessels in NBTLs [(A) x300], DCIS [(B) x300] and IDC [(C) x300]. Nestin expression in myoepithelial cells is also observed [(A and B) green arrows]. Nestin [(D) x250], CD34 [(E) x250] and CD31 [(F) x250)] expression in blood vessels (red arrows, serial sections).

FITC (1:200, polyclonal; P8547 Sigma). The cells were analyzed by flow cytometry using FACSCalibur (Becton-Dickinson) equipped with a 488-nm laser and filter for FITC analysis (530 BP). As single labelling was performed, no compensation setting was required. Data were recorded for 10,000 events using CellQuest version 3.3 software (Becton-Dickinson), analyzed on the ungated population (except for debris) and presented without any transformation as histograms using WINMDI 2.7 (Scripps Institute, CA, USA) software. Mean fluorescence intensity (MFI) for nestin is shown as a difference between MFI for samples incubated with primary and secondary antibodies and MFI for isotype control.

Statistical analysis. The data were analyzed with Prism 5.0 (GraphPad, La Jolla, CA, USA) software. The KolmogorovSmirnov test was applied to determine whether sample data are normally distributed. To evaluate the relationships and correlations between the examined markers and with clinicopathological factors, Student's t-test and Spearman rank correlation test were utilized. The Kaplan-Meier method and the Mantel-Cox test were used to determine the significance of patient OS and event-free survival (EFS). A Cox proportional hazards model with forward stepwise selection was used to calculate univariate and multivariate hazard ratio for the study variables. Differences were considered statistically significant at $\mathrm{p}<0.05$.

\section{Results}

IHC. Nestin expression was observed in the cytoplasm of ECs in all study cases (Fig. 1A-D). In addition, nestin expression was observed in myoepithelial cells of the ducts and lobular acinar units (Fig. 1A and B) and in some cases in tumour cells (data not shown). A significantly higher Nes ${ }^{+}$MVD was observed in both groups of IDC patients i.e., IDC $\mathrm{N}^{-}$and IDC $\mathrm{N}^{+}$in relation to the control group comprising NBTLs (Fig. 2A; 72.32 \pm 25.01 ; $86.12 \pm 31.60$ vs. $33.85 \pm 14.83 ; \mathrm{p}<0.0001, \mathrm{p}<0.0001$, respectively,
Student's t-test). It was also demonstrated that $\mathrm{Nes}^{+} \mathrm{MVD}$ was higher in both groups with IDC (IDCN ${ }^{+}$and IDC $\mathrm{N}^{-}$) as compared to the group with DCIS (Fig. 2A, 86.12 $\pm 31.60 ; 72.32 \pm 25.01$ vs. $43.52 \pm 18.21 ; \mathrm{p}<0.0001, \mathrm{p}<0.0001$, Student's t-test). We also showed that $\mathrm{Nes}^{+} \mathrm{MVD}$ was significantly higher in the group of patients with IDC $\mathrm{N}^{+}$than with IDC $\mathrm{N}^{-}$(Fig. 2A, 86.12 \pm 31.60 vs. $72.32 \pm 25.01 ; \mathrm{p}=0.0132$, Student's t-test). Additionally, in the group of IDC, Nes ${ }^{+} \mathrm{MVD}$ was significantly higher in the case of G3 and G2 tumours than in G1 tumours (Fig. 2B, 86.63 \pm 32.96 ; $78.84 \pm 28.88$ vs. $57.14 \pm 20.87 ; p=0.0072, p=0.0203$, Student's t-test). A lower value of Nes ${ }^{+} \mathrm{MVD}$ was found in patients with early-stage disease (I and II) than in patients with advancedstage disease (III and IV; Fig. 2C, $75.99 \pm 27.62$ vs. $92.02 \pm 35.05$; $\mathrm{p}=0.0377$, Student's t-test)

Among patients with IDC, a high Nes ${ }^{+}$MVD was also related to the TN phenotype of breast cancer characterized by a lack of ER, PR and HER2 expression (Fig. 2D, 76.91 \pm 28.97 vs. $93.83 \pm 39.58 ; p=0.0357$ Student's $t$-test). The analysis of survival data in the group of IDC patients showed that a high value of $\mathrm{Nes}^{+} \mathrm{MVD}$ was associated with shorter OS (Fig. 3A, $\mathrm{p}=0.0013$, Mantel-Cox) and shorter EFS (Fig. 3B, $\mathrm{p}=0.0091$; median 75.76; Mantel-Cox). Moreover, in the case of OS, nestin turned out to be an independent prognostic factor (Table III, $\mathrm{p}=0.007$, multivariate Cox analysis). Additionally, the correlation analysis showed that $\mathrm{Nes}^{+} \mathrm{MVD}$ in IDC correlates with the density of $\mathrm{CD} 34^{+}$vessels (Fig. 4A, r=0.3280; $\mathrm{p}=0.0032$, Spearman rank test) whereas no correlation was noted between $\mathrm{Nes}^{+} \mathrm{MVD}$ and the density of $\mathrm{CD} 31^{+}$vessels (Fig. 4B, r=0.1563; p=0.1304, Spearman rank test).

Real-time PCR. The real-time PCR was performed to evaluate NES expression level in human endothelial cell lines. The relative NES expression was assessed in relation to the HUVEC-SVT cell line. The analysis showed significant differences in NES expression between all the investigated cell lines i.e., HUVEC-SVT, HMEC-1 and HEPC-CB.1 (Fig. 5, p $<0.0001$, Student's t-test). The highest NES expression 

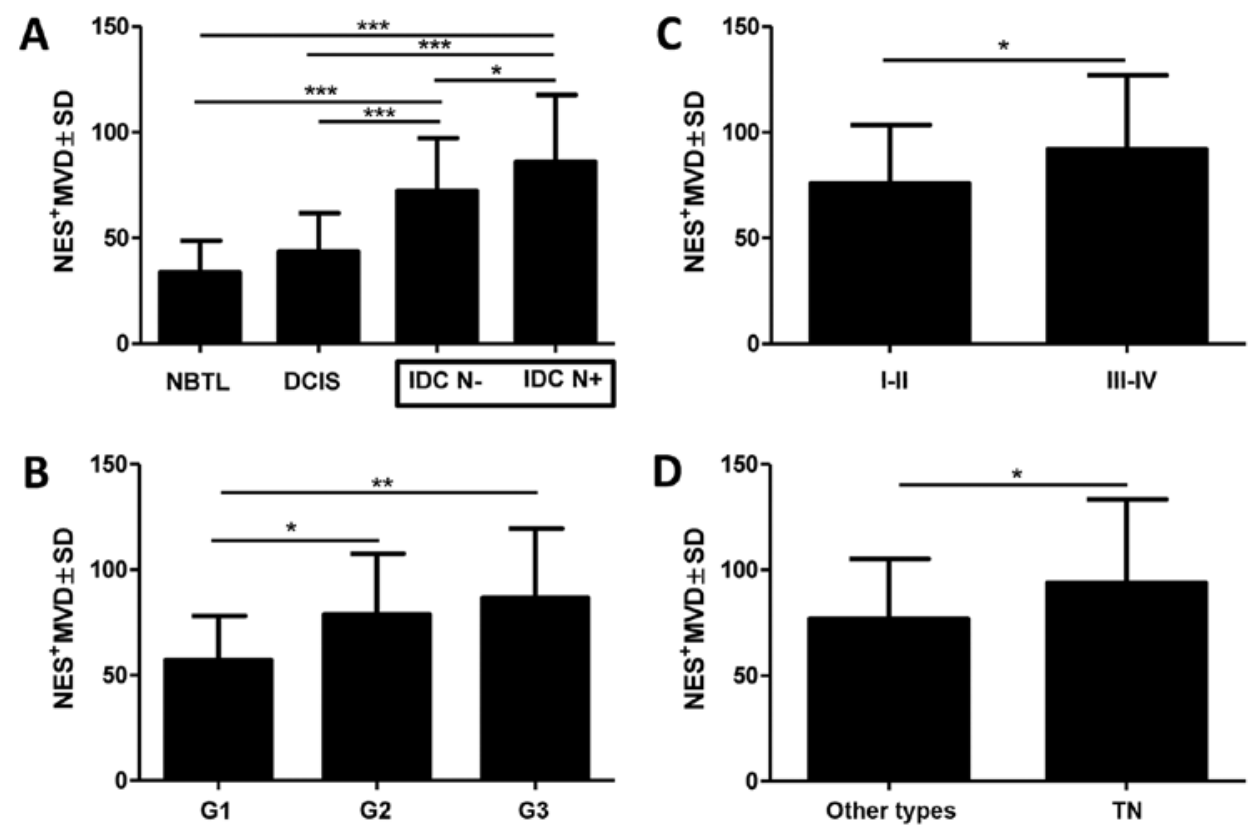

Figure 2. Nes ${ }^{+} \mathrm{MVD}$ increases with the increase in invasiveness of lesions in the breast [(A) Student's t-test]. Nes ${ }^{+} \mathrm{MVD}$ is higher in lesions with higher histological grade [(B) Student's t-test], in advanced-stage disease patients [(C) Student's t-test] and in TN breast cancers [(D) Student's t-test]; ${ }^{*} \mathrm{p}<0.05,{ }^{* *} \mathrm{p}<0.01,{ }^{* * *} \mathrm{p}<0.001$.
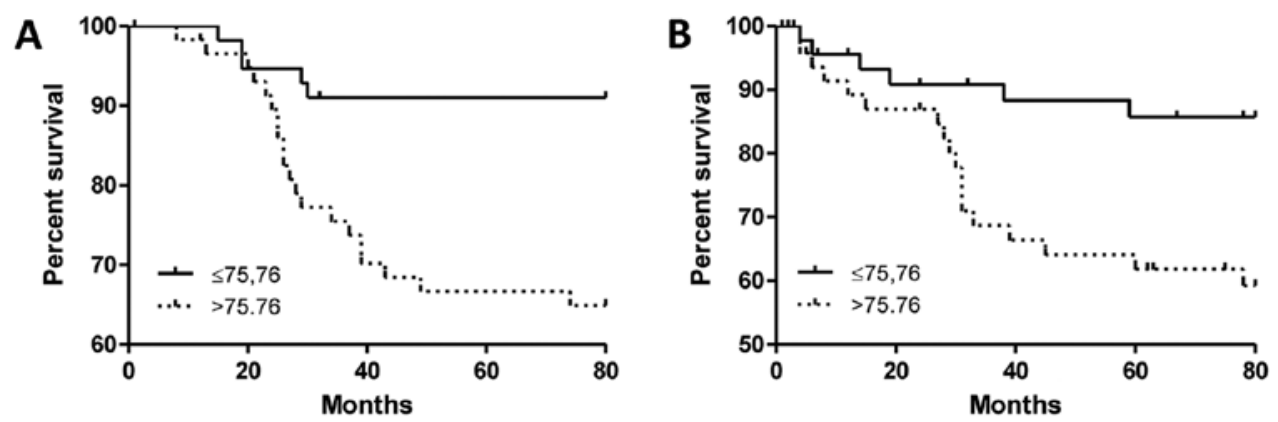

Figure 3. Nes ${ }^{+} \mathrm{MVD}$ is related to a shorter OS of patients [(A) $\mathrm{p}=0.0013$, Mantel-Cox] and EFS [(B) $\mathrm{p}=0.0091$, Mantel-Cox)].
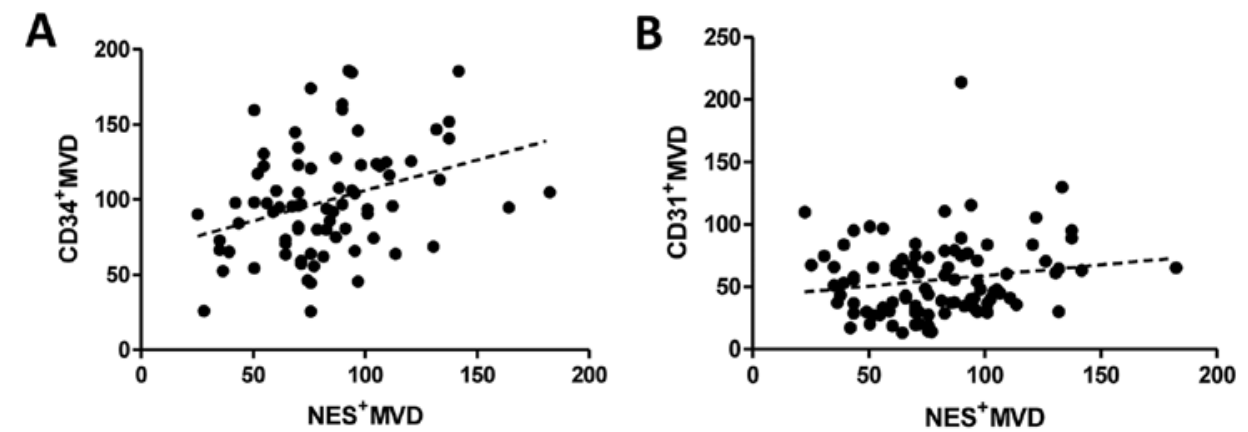

Figure 4. Nes ${ }^{+}$MVD correlates with the density of newly forming CD34 ${ }^{+}$vessels [(A) $r=0.3280 ; p=0.0032$, Spearman rank test], but not with the density of $\mathrm{CD} 31^{+}$mature vessels $[(\mathrm{B}) \mathrm{r}=0.1563 ; \mathrm{p}=0.1304$, Spearman rank test $]$.

was observed in the progenitor HEPC-CB.1 cells isolated from human umbilical cord blood, and a trace expression in the HMEC-1 line isolated from dermal microvessels.

IF and ICC. Experiments using ICC and IF showed a cytoplasmic expression of nestin in all the examined cell lines (Fig. 6). The most intense reaction was observed in the progenitor HEPC-CB.1 cells, mildly intense in the HMEC-1 cells and the weakest in the HUVEC-SVT cells.

$F C$. To confirm the different expression level of nestin in the examined cell lines, we used flow cytometric assay. Measurements of the MFI showed a lack of nestin expression in the HUVEC-SVT cells and a very weak nestin expression 
Table III. Uni- and multivariate Cox analysis of overall survival.

\begin{tabular}{|c|c|c|c|c|c|c|c|c|}
\hline \multirow[b]{2}{*}{ Characteristics } & \multicolumn{4}{|c|}{$\begin{array}{l}\text { Univariate Cox analysis } \\
\text { p-value }\end{array}$} & \multicolumn{4}{|c|}{$\begin{array}{c}\text { Multivariate Cox analysis } \\
\text { HR }\end{array}$} \\
\hline & $\mathrm{p}$-value & HR & $95 \%$ CI lower & $95 \%$ CI upper & $\mathrm{p}$-value & HR & $95 \%$ CI lower & $95 \%$ CI upper \\
\hline $\begin{array}{l}\text { Age } \\
\leq 50 \text { vs }>50\end{array}$ & 0.714 & 0.978 & 0.869 & 1.101 & & & & \\
\hline $\begin{array}{l}\text { Menopausal status } \\
\text { Pre vs post }\end{array}$ & 0.687 & 0.832 & 0.340 & 2.034 & & & & \\
\hline G & 0.032 & 2.220 & 1.073 & 4.595 & 0.042 & 2.417 & 1.034 & 5.649 \\
\hline $\begin{array}{l}\text { Stage } \\
\text { I-II vs III-IV }\end{array}$ & 0.0001 & 7.675 & 3.357 & 17.549 & 0.004 & 6.971 & 1.865 & 26.063 \\
\hline $\mathrm{pT}$ & 0.0001 & 3.787 & 2.281 & 6.288 & 0.041 & 2.045 & 1.029 & 4.062 \\
\hline $\begin{array}{l}\mathrm{pN} \\
\mathrm{N} 0 \text { vs N1-3 }\end{array}$ & 0.129 & 1.015 & 0.995 & 1.035 & & & & \\
\hline $\begin{array}{l}\text { ER } \\
\text { Negative vs positive }\end{array}$ & 0.0118 & 0.346 & 0.152 & 0.790 & 0.446 & 0.582 & 0.145 & 2.338 \\
\hline $\begin{array}{l}\text { PR } \\
\text { Negative vs positive }\end{array}$ & 0.039 & 0.423 & 0.187 & 0.959 & 0.14 & 0.384 & 0.108 & 1.368 \\
\hline $\begin{array}{l}\text { HER2 } \\
\text { Negative vs positive }\end{array}$ & 0.209 & 1.816 & 0.716 & 4.609 & & & & \\
\hline Triple-negative & 0.069 & 2.376 & 0.936 & 6.031 & 0.03 & 0.182 & 0.039 & 0.849 \\
\hline $\begin{array}{l}\text { CD } 34^{+} \text {MVD } \\
<95.44 \text { vs }>95.44\end{array}$ & 0.315 & 1.655 & 0.62 & 4.421 & & & & \\
\hline $\begin{array}{l}\text { CD } 31^{+} \text {MVD } \\
<48.42 \text { vs }>48.42\end{array}$ & 0.244 & 1.718 & 0.691 & 4.272 & & & & \\
\hline $\begin{array}{l}\mathrm{Nes}^{+} \mathrm{MVD} \\
<75.76 \text { vs }>75.76\end{array}$ & 0.002 & 4.960 & 1.84 & 13.37 & 0.007 & 4.303 & 1.478 & 12.52 \\
\hline
\end{tabular}

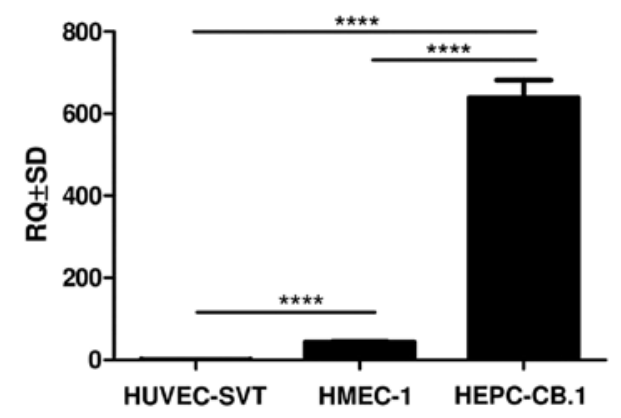

Figure 5. Expression of NES mRNA in human endothelial cell lines (Student's $\mathrm{t}$-test, $\left.{ }^{* * * *} \mathrm{p}<0.0001\right)$.

in HMEC-1 cells (Table IV and Fig. 6). A high MFI of nestin was observed in the progenitor HEPC-CB.1 cells (Table IV and Fig. 6).
Table IV. Mean values of fluorescence for isotype control and nestin in HUVEC-SVT, HMEC-1 and HEPC-CB.1 cell lines.

\begin{tabular}{lccr}
\hline Cell line & Isotype control & I+II antibody & Nestin \\
\hline HUVEC-SVT & 6.08 & 7.20 & 1.12 \\
HMEC-1 & 3.93 & 9.86 & 5.93 \\
HEPC-CB.1 & 7.10 & 51.20 & 44.10 \\
\hline
\end{tabular}

\section{Discussion}

Initially, nestin expression in the proliferating endothelium of blood vessels in human tumours was reported in the tumours of the central nervous system (26) and rhabdomyosarcoma (27). Further studies on animal models showed that nestin expression 

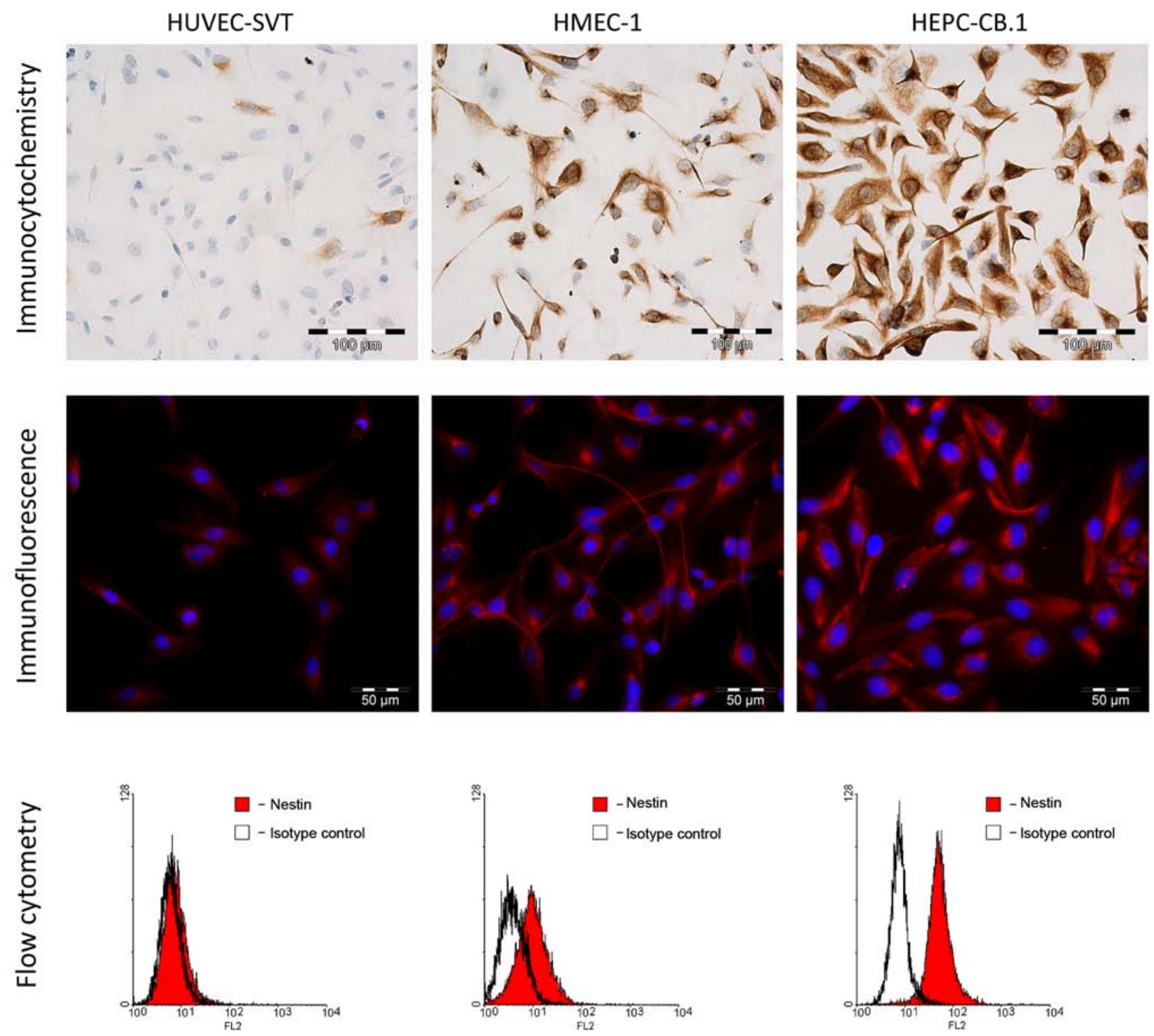

Figure 6. Cytoplasmic nestin expression in HUVEC-SVT, HMEC-1 and HEPC-CB.1 cell lines examined with the use of ICC, IF and FC.

in cerebellar blood vessels can be induced by pro-angiogenic factors (28). Then Mokry et al confirmed that nestin undergoes expression in blood vessels in many human tissues and organs in which angiogenesis occurs (13). The first attempt at determining the density of $\mathrm{Nes}^{+}$vessels and comparing it with the density of $\mathrm{CD} 4^{+}$vessels was assessed in patients with gastric adenocarcinoma (17). However, this study demonstrated no prognostic value for either antigen, but in the case of large tumours nestin showed some prognostic value. Further studies revealed that the high density of proliferating microvessels co-expressing nestin and Ki-67 antigen was associated with a worse prognosis in patients with prostate (29) and breast cancers (30). Previous studies on nestin expression in breast cancer tumour cells revealed that nestin correlates with TN subtype and worse prognosis $(15,31,32)$. However, Kruger et al demonstrated in a large population-based study that nestin expression in tumour cells strongly correlates with basal-like molecular subtype of TN breast cancers, with BRCA1-related breast cancer and with reduced survival (33) In our study, we also noted nestin expression in some of tumour cells (data not shown).
In the study, we assessed the prognostic value of $\mathrm{Nes}^{+} \mathrm{MVD}$ in patients with ductal breast carcinoma. Our results suggest that in ductal breast carcinoma Nes ${ }^{+}$MVD increases with tumour invasiveness. The lowest value of $\mathrm{Nes}^{+} \mathrm{MVD}$ was observed in non-malignant lesions and in in situ carcinomas, while in invasive cancers it was significantly higher. These results are consistent with the Folkman hypothesis, according to which increased tumour vascularity is necessary for its transition from in situ to invasive cancer (1). When tumour cells become invasive, they start to migrate in the extracellular matrix and invade blood and lymphatic vessels, thus resulting in the formation of metastases. Increased blood and lymphatic vessel density within the tumour area increases the probability of vessel invasion, and thus the probability of invading lymph nodes and developing metastases (34). In this study, we demonstrated that $\mathrm{Nes}^{+} \mathrm{MVD}$ in IDC was higher in patients with lymph node metastases than in cases without lymph node invasion. Similar results for MVD, but for different endothelial antigens (i.e., CD31 and CD34) were obtained by Weidner et al (6), Popiela et al (35) and Xie et al (36). 
Furthermore, we demonstrated that $\mathrm{Nes}^{+} \mathrm{MVD}$ increases with the histological grade of IDC and achieves the highest value in the G3 and the lowest in G1 tumours. Similar results, but with the use of $\mathrm{Nes}^{+} \mathrm{Ki}-67^{+}$vascular proliferation index (VPI) were reported in breast cancers by Kruger et al (30). In their study, VPI was calculated as the ratio between the number of $\mathrm{Nes}^{+}$microvessels containing $\mathrm{Ki}-67^{+}$proliferating endothelial cells ( $\left.\mathrm{Nes}^{+} \mathrm{Ki}-67^{+} \mathrm{MVD}\right)$ and the total number of $\mathrm{Nes}^{+}$microvessels ( $\mathrm{Nes}^{+} \mathrm{MVD}$ ) expressed as a percentage (Nes $\left.{ }^{+} \mathrm{Ki}-67^{+} \mathrm{MVD} / \mathrm{Nes}^{+} \mathrm{MVD}\right)$. They shown that high value of VPI but not Nes ${ }^{+}$MVD itself, correlates with aggressive features and poor outcome of breast cancer (30). Additionally, we found significantly higher $\mathrm{Nes}^{+} \mathrm{MVD}$ values in patients with the advanced-stage disease as compared to patients with the early-stage disease. Interestingly, we also noted that the number of $\mathrm{Nes}^{+}$vessels was associated with molecular subtype of breast cancer. A high Nes ${ }^{+}$MVD was observed in patients with TN breast cancer. TN is an extremely aggressive cancer subtype with a poor prognosis. Similarly to our results, Kruger et al demonstrated that the highest MVD of both $\mathrm{Nes}^{+}$and $\mathrm{Nes}^{+} \mathrm{Ki}-67^{+}$vessels and a higher VPI were noted in TN and basal-like cancers (30). Furthermore, in contrast to their results, we found that in IDC Nes ${ }^{+} \mathrm{MVD}$ is an independent prognostic factor. In our study, high $\mathrm{Nes}^{+} \mathrm{MVD}$ was associated with a shorter OS and earlier relapse. On the contrary, Kruger et al (30) did not demonstrate statistically significant relationship between $\mathrm{Nes}^{+} \mathrm{MVD}$ and patient survival. This might be due to the use of a more restrictive cut-off values determining high Nes ${ }^{+}$MVD values and that they obtained higher median value of $\mathrm{Nes}^{+}$microvessels $\left(84.3>75.8 \mathrm{v} / \mathrm{mm}^{2}\right)$. However, the same authors showed that in the case of nestin VPI might be a valuable prognostic factor (30). The different results might be due to the fact, that in our study we took into account only ductal carcinoma cases (from 0.4 to $8 \mathrm{~cm}$ in diameter), whereas Kruger et al (30) selected both ductal and lobular histological types and tumours oscillating $\sim 2 \mathrm{~cm}$ in diameter during screening mammography. Finally, we are the first to report that the number of $\mathrm{Nes}^{+}$microvessels is noticeably higher in invasive tumours than in pre-invasive lesions and that $\mathrm{Nes}^{+} \mathrm{MVD}$ correlates with immature $\mathrm{CD} 34^{+}$vessels but not with mature $\mathrm{CD} 31^{+}$vessels.

To date, CD34 and CD31 antigens have been commonly used for the assessment of angiogenesis. However, these markers are not selective for newly forming vessels and they do not constitute a reliable reflection of tumour angiogenesis. During EC differentiation, cells initially express CD34 antigen whereas the expression of CD31 occurs at later stages of EC development (22). The findings suggest that the expression of CD31 antigen is typical of more mature vessels, while CD34 expression is related to a more primary vascular phenotype (37-40). Our results demonstrated that $\mathrm{Nes}^{+} \mathrm{MVD}$ correlates with the density of newly forming $\mathrm{CD} 34^{+}$vessels, whereas no correlation was found in the case of $\mathrm{CD} 31^{+}$mature vessels. It may indicate that nestin expression reflects a more progenitor nature of vessels and that it is mainly limited to those undifferentiated and newly forming ones. To confirm the obtained results, we developed an in vitro model consisting of three endothelial cell lines isolated from different types of vessels. Examinations of nestin expression showed that the highest expression occurs in the HEPC-CB.1 cell line, originating from human umbilical cord blood. This line was characterized as early EPCs and shows the expression of both stem cell (e.g., CD133) and endothelial antigens (e.g., VEGFR2, nitric oxide synthase) (22). We noted a lower nestin expression in the HMEC-1 cells isolated from dermal microvessels and the HUVEC-SVT cells isolated from the umbilical vein, respectively. HUVEC-SVT and HMEC-1 cell lines are derived from different blood vessel types, but both represent mature and differentiated phenotypes of vessels. Similarly, Suzuki et al demonstrated that in the bone marrow nestin is expressed exclusively in proliferating progenitor ECs, but not in mature ECs (20). Moreover, the literature data indicate that nestin undergoes expression not only in EPCs, but also in mesenchymal stem cells (MSCs) which may differentiate into pericytes and vascular smooth muscle cells (41). Thus, $\mathrm{Nes}^{+}$cells may participate not only in the formation of the endothelium but also in the stabilization of the entire vessel wall.

In conclusion, we assume that nestin might be a reliable marker for angiogenesis evaluation in IDC and higher $\mathrm{Nes}^{+} \mathrm{MVD}$ may be related to a more aggressive course of the disease and a poorer prognosis. Additionally, nestin seems to be a selective marker for newly forming vessels and its expression may reflect the process of tumour angiogenesis.

\section{References}

1. Folkman J: Tumor angiogenesis: Therapeutic implications. N Engl J Med 285: 1182-1186, 1971.

2. Hanahan D and Weinberg RA: Hallmarks of cancer: The next generation. Cell 144: 646-674, 2011.

3. Shih T and Lindley C: Bevacizumab: An angiogenesis inhibitor for the treatment of solid malignancies. Clin Ther 28: 1779-1802, 2006.

4. Shaheen RM, Ahmad SA, Liu W, Reinmuth N, Jung YD, Tseng WW, Drazan KE, Bucana CD, Hicklin DJ and Ellis LM: Inhibited growth of colon cancer carcinomatosis by antibodies to vascular endothelial and epidermal growth factor receptors. Br J Cancer 85: 584-589, 2001.

5. Uzzan B, Nicolas P, Cucherat M and Perret GY: Microvessel density as a prognostic factor in women with breast cancer: A systematic review of the literature and meta-analysis. Cancer Res 64: 2941-2955, 2004.

6. Weidner N, Semple JP, Welch WR and Folkman J: Tumor angiogenesis and metastasis--correlation in invasive breast carcinoma. N Engl J Med 324: 1-8, 1991.

7. Meert AP, Paesmans M, Martin B, Delmotte P, Berghmans T, Verdebout JM, Lafitte JJ, Mascaux C and Sculier JP: The role of microvessel density on the survival of patients with lung cancer: A systematic review of the literature with meta-analysis. Br J Cancer 87: 694-701, 2002.

8. Lendahl U, Zimmerman LB and McKay RD: CNS stem cells express a new class of intermediate filament protein. Cell 60: 585-595, 1990.

9. Sejersen T and Lendahl U: Transient expression of the intermediate filament nestin during skeletal muscle development. J Cell Sci 106: 1291-1300, 1993 .

10. Terling C, Rass A, Mitsiadis TA, Fried K, Lendahl U and Wroblewski J: Expression of the intermediate filament nestin during rodent tooth development. Int J Dev Biol 39: 947-956, 1995.

11. Fröjdman K, Pelliniemi LJ, Lendahl U, Virtanen I and Eriksson JE: The intermediate filament protein nestin occurs transiently in differentiating testis of rat and mouse. Differentiation 61: 243-249, 1997.

12. Lardon J, Rooman I and Bouwens L: Nestin expression in pancreatic stellate cells and angiogenic endothelial cells. Histochem Cell Biol 117: 535-540, 2002 .

13. Mokrý J, Cízková D, Filip S, Ehrmann J, Osterreicher J, Kolár Z and English D: Nestin expression by newly formed human blood vessels. Stem Cells Dev 13: 658-664, 2004. 
14. Krupkova O Jr, Loja T, Zambo I and Veselska R: Nestin expression in human tumors and tumor cell lines. Neoplasma 57: 291-298, 2010

15. Liu C, Chen B, Zhu J, Zhang R, Yao F, Jin F, Xu H and Lu P: Clinical implications for nestin protein expression in breast cancer. Cancer Sci 101: 815-819, 2010.

16. Sjöberg G, Jiang WQ, Ringertz NR, Lendahl U and Sejersen T: Colocalization of nestin and vimentin/desmin in skeletal muscle cells demonstrated by three-dimensional fluorescence digital imaging microscopy. Exp Cell Res 214: 447-458, 1994.

17. Kim HS, Kang HS, Messam CA, Min KW and Park CS: Comparative evaluation of angiogenesis in gastric adenocarcinoma by nestin and CD34. Appl Immunohistochem Mol Morphol 10: 121-127, 2002.

18. Klein T, Ling Z, Heimberg H, Madsen OD, Heller RS and Serup P: Nestin is expressed in vascular endothelial cells in the adult human pancreas. J Histochem Cytochem 51: 697-706, 2003.

19. Teranishi N, Naito Z, Ishiwata T, Tanaka N, Furukawa K, Seya T, Shinji $\mathrm{S}$ and Tajiri T: Identification of neovasculature using nestin in colorectal cancer. Int J Oncol 30: 593-603, 2007.

20. Suzuki S, Namiki J, Shibata S, Mastuzaki Y and Okano H: The neural stem/progenitor cell marker nestin is expressed in proliferative endothelial cells, but not in mature vasculature. J Histochem Cytochem 58: 721-730, 2010.

21. Bouïs D, Hospers GA, Meijer C, Molema G and Mulder NH: Endothelium in vitro: A review of human vascular endothelial cell lines for blood vessel-related research. Angiogenesis 4: 91-102, 2001.

22. Paprocka M, Krawczenko A, Dus D, Kantor A, Carreau A, Grillon $\mathrm{C}$ and Kieda C: CD133 positive progenitor endothelial cell lines from human cord blood. Cytometry A 79: 594-602, 2011.

23. Goldhirsch A, Ingle JN, Gelber RD, Coates AS, Thürlimann B and Senn HJ; Panel members: Thresholds for therapies: Highlights of the St Gallen International Expert Consensus on the primary therapy of early breast cancer 2009. Ann Oncol 20: 1319-1329, 2009.

24. Mueller-Holzner E, Fink V, Frede T and Marth C: Immunohistochemical determination of HER2 expression in breast cancer from core biopsy specimens: A reliable predictor of HER2 status of the whole tumor. Breast Cancer Res Treat 69: 13-19, 2001.

25. Schmittgen TD and Livak KJ: Analyzing real-time PCR data by the comparative C(T) method. Nat Protoc 3: 1101-1108, 2008.

26. Dahlstrand J, Collins VP and Lendahl U: Expression of the class VI intermediate filament nestin in human central nervous system tumors. Cancer Res 52: 5334-5341, 1992.

27. Kobayashi M, Sjöberg G, Söderhäll S, Lendahl U, Sandstedt B and Sejersen T: Pediatric rhabdomyosarcomas express the intermediate filament nestin. Pediatr Res 43: 386-392, 1998.

28. Mokrý $\mathbf{J}$ and Nemecek $\mathbf{S}$ : Cerebral angiogenesis shows nestin expression in endothelial cells. Gen Physiol Biophys 18 (Suppl 1): 25-29, 1999.
29. Gravdal K, Halvorsen OJ, Haukaas SA and Akslen LA: Proliferation of immature tumor vessels is a novel marker of clinical progression in prostate cancer. Cancer Res 69: 4708-4715, 2009.

30. Krüger K, Stefansson IM, Collett K, Arnes JB, Aas T and Akslen LA: Microvessel proliferation by co-expression of endothelial nestin and $\mathrm{Ki}-67$ is associated with a basal-like phenotype and aggressive features in breast cancer. Breast 22: 282-288, 2013.

31. Piras F, Ionta MT, Lai S, Perra MT, Atzori F, Minerba L, Pusceddu V, Maxia C, Murtas D, Demurtas P, et al: Nestin expression associates with poor prognosis and triple-negative phenotype in locally advanced (T4) breast cancer. Eur J Histochem 55: e39, 2011.

32. Parry S, Savage K, Marchiò C and Reis-Filho JS: Nestin is expressed in basal-like and triple-negative breast cancers. J Clin Pathol 61: 1045-1050, 2008.

33. Krüger K, Wik E, Knutsvik G, Nalwoga H, Klingen TA, Arnes JB, Chen Y, Mannelqvist M, Dimitrakopoulou K, Stefansson IM, et al: Expression of Nestin associates with BRCA1 mutations, a basal-like phenotype and aggressive breast cancer. Sci Rep 7: 1089, 2017.

34. Paduch R: The role of lymphangiogenesis and angiogenesis in tumor metastasis. Cell Oncol (Dordr) 39: 397-410, 2016.

35. Popiela TJ, Sikora J, Klimek M, Basta P, Niemiec T, Dobrogowski J, Kotlarz A, Rudnicka-Sosin L and DutschWicherek M: The analysis of CD34 antigen immunoreactivity level in invasive ductal breast cancer with respect to the presence of lymph node metastases. Neuro Endocrinol Lett 29: 443-446, 2008.

36. Xie XD, Qu SX, Liu ZZ, Zhang F and Zheng ZD: Study on relationship between angiogenesis and micrometastases of peripheral blood in breast cancer. J Cancer Res Clin Oncol 135: 413-419, 2009.

37. Ribatti D: The discovery of endothelial progenitor cells. An historical review. Leuk Res 31: 439-444, 2007.

38. Nagatsuka H, Hibi K, Gunduz M, Tsujigiwa H, Tamamura R, Sugahara T, Sasaki A and Nagai N: Various immunostaining patterns of CD31, CD34 and endoglin and their relationship with lymph node metastasis in oral squamous cell carcinomas. J Oral Pathol Med 34: 70-76, 2005.

39. Walzer SM, Cetin E, Grübl-Barabas R, Sulzbacher I, Rueger B, Girsch W, Toegel S, Windhager R and Fischer MB: Vascularization of primary and secondary ossification centres in the human growth plate. BMC Dev Biol 14: 36, 2014.

40. Corselli M, Chen CW, Crisan M, Lazzari L and Péault B: Perivascular ancestors of adult multipotent stem cells. Arterioscler Thromb Vasc Biol 30: 1104-1109, 2010.

41. Klein D, Meissner N, Kleff V, Jastrow H, Yamaguchi M, Ergün S and Jendrossek V: Nestin(+) tissue-resident multipotent stem cells contribute to tumor progression by differentiating into pericytes and smooth muscle cells resulting in blood vessel remodeling. Front Oncol 4: 169, 2014. 